\title{
Spatial and Temporal Variability in Migration of a Soaring Raptor Across Three Continents
}

\section{OPEN ACCESS}

Edited by:

Nathan R. Senner,

University of South Carolina,

United States

Reviewed by:

Wouter Marc Gerard Vansteelant,

Estación Biológica de Doñana

(EBD), Spain

Tom Finch,

Royal Society for the Protection of

Birds (RSPB), United Kingdom

${ }^{*}$ Correspondence:

W. Louis Phipps

l.phipps@4vultures.org

†These authors have contributed equally to this work

Specialty section:

This article was submitted to Behavioral and Evolutionary Ecology,

a section of the journal

Frontiers in Ecology and Evolution

Received: 18 April 2019

Accepted: 13 August 2019

Published: 10 September 2019

Citation:

Phipps WL, López-López $P$

Buechley ER, Oppel S, Álvarez E,

Arkumarev $V$, Bekmansurov $R$, Berger-Tal O, Bermejo A, Bounas A, Alanís IC, de la Puente J, Dobrev V, Duriez O, Efrat R, Fréchet G, García J,

Galán M, García-Ripollés C, Gil A, Iglesias-Lebrija JJ, Jambas J, Karyakin IV, Kobierzycki E, Kret E

Loercher F, Monteiro A, Morant Etxebarria J, Nikolov SC, Pereira J,

Peške L, Ponchon C, Realinho E,

Saravia V, Şekercioğlu ÇH, Skartsi T,

Tavares J, Teodósio J, Urios $V$ and Vallverdú N (2019) Spatial and

Temporal Variability in Migration of a Soaring Raptor Across Three

Continents. Front. Ecol. Evol. 7:323.

doi: 10.3389/fevo.2019.00323
W. Louis Phipps ${ }^{1 * t}$, Pascual López-López ${ }^{2 t}$, Evan R. Buechley ${ }^{3,4 t}$, Steffen Oppel ${ }^{5 t}$, Ernesto Álvarez ${ }^{6}$, Volen Arkumarev ${ }^{7}$, Rinur Bekmansurov ${ }^{8}$, Oded Berger-Tal ${ }^{9}$, Ana Bermejo ${ }^{10}$, Anastasios Bounas ${ }^{11,12}$, Isidoro Carbonell Alanís ${ }^{13}$, Javier de la Puente ${ }^{10}$, Vladimir Dobrev ${ }^{7}$, Olivier Duriez ${ }^{14}$, Ron Efrat ${ }^{9}$, Guillaume Fréchet ${ }^{15}$, Javier Garcia ${ }^{16}$, Manuel Galán ${ }^{6}$, Clara García-Ripollés ${ }^{17}$, Alberto Gil ${ }^{6}$, Juan José Iglesias-Lebrija ${ }^{6}$, José Jambas ${ }^{18}$, Igor V. Karyakin ${ }^{19}$, Erick Kobierzycki ${ }^{20}$, Elzbieta Kret ${ }^{21}$, Franziska Loercher ${ }^{1}$, Antonio Monteiro ${ }^{22}$, Jon Morant Etxebarria ${ }^{23}$, Stoyan C. Nikolov ${ }^{7}$, José Pereira ${ }^{24}$, Lubomír Peške ${ }^{25}$, Cecile Ponchon ${ }^{26}$, Eduardo Realinho ${ }^{27}$, Victoria Saravia ${ }^{12}$, Çağan H. Şekercioğlu ${ }^{28,29}$, Theodora Skartsi ${ }^{21}$, José Tavares ${ }^{1}$, Joaquim Teodósio ${ }^{30}$, Vicente Urios ${ }^{31}$ and Núria Vallverdú ${ }^{27}$

${ }^{1}$ Vulture Conservation Foundation, Zurich, Switzerland, ${ }^{2}$ Terrestrial Vertebrates Group, Cavanilles Institute of Biodiversity and Evolutionary Biology, University of Valencia, Valencia, Spain, ${ }^{3}$ Smithsonian Migratory Bird Center, Washington, DC, United States, ${ }^{4}$ HawkWatch International, Salt Lake City, UT, United States, ${ }^{5}$ Royal Society for the Protection of Birds, RSPB Centre for Conservation Science, Cambridge, United Kingdom, ${ }^{6}$ Grupo de Rehabilitación de la Fauna Autóctona y su Hábitat, Madrid, Spain, ${ }^{7}$ Bulgarian Society for Protection of Birds/BirdLife Bulgaria, Sofia, Bulgaria, ${ }^{8}$ Educational and Scientific Laboratory - Monitoring and Protection of Birds, Elabuga Institute, Kazan Federal University, Elabuga, Russia, ${ }^{9}$ Mitrani Department of Desert Ecology, Jacob Blaustein Institutes for Desert Research, Ben-Gurion University of the Negev, Midreshet Ben-Gurion, Israel, ${ }^{10}$ Bird Monitoring Unit, SEO/BirdLife, Madrid, Spain, ${ }^{11}$ Department of Biological Applications and Technologies, University of loannina, Ioannina, Greece, ${ }^{12}$ Hellenic Ornithological Society, BirdLife Greece, Athens, Greece, ${ }^{13}$ SALORO, Salamanca, Spain, ${ }^{14}$ UMR 5175, Centre d'Ecologie Fonctionnelle et Evolutive, CNRS - Université de Montpellier, Université Paul-Valéry Montpellier - EPHE, Montpellier, France, ${ }^{15}$ Syndicat Mixte des Gorges du Gardon, Gard, France, ${ }^{16}$ Department of Biodiversity and Environmental Management, University of León, León, Spain, ${ }^{17}$ Environment Science and Solutions, Valencia, Spain, ${ }^{18}$ Oriolus Ambiente e Ecoturismo, Atenor, Picote, Portugal, ${ }^{19}$ Sibecocentar LLC, Novosibirsk, Russia, ${ }^{20}$ Nature en Occitanie, Coordination Technique Plan National d'Actions Vautour Percnoptère, Bruges, France, ${ }^{21}$ WWF Greece, Athens, Greece, ${ }^{22}$ Instituto da Conservação da Natureza e das Florestas, Lisbon, Portugal, ${ }^{23}$ Department of Ornithology, Aranzadi Sciences Society, Donostia-San Sebastián, Spain, ${ }^{24}$ Palombar, Associação da Conservação da Natureza e do Património Rural, Antiga Escola Primária de Uva, Uva, Portugal, ${ }^{25}$ Independent Researcher, Prague, Czechia, ${ }^{26}$ Conservatoire Espaces Naturels Provence-Alpes-Côte d'Azur, Aix-en-Provence, France, ${ }^{27}$ Transumância e Natureza - Associação (ATN), Figueira de Castelo Rodrigo, Portugal, ${ }^{28}$ Department of Biology, University of Utah, Salt Lake City, UT, United States, ${ }^{29}$ College of Sciences, Koç University, Istanbul, Turkey, ${ }^{30}$ Sociedade Portuguesa para o Estudo das Aves (SPEA), Lisbon, Portugal, ${ }^{31}$ Vertebrate Zoology Research Group, University of Alicante, Alicante, Spain

Disentangling individual- and population-level variation in migratory movements is necessary for understanding migration at the species level. However, very few studies have analyzed these patterns across large portions of species' distributions. We compiled a large telemetry dataset on the globally endangered Egyptian Vulture Neophron percnopterus (94 individuals, 188 completed migratory journeys), tracked across $\sim 70 \%$ of the species' global range, to analyze spatial and temporal variability of migratory movements within and among individuals and populations. We found high migratory connectivity at large spatial scales (i.e., different subpopulations showed little overlap in wintering areas), but very diffuse migratory connectivity within subpopulations, with wintering ranges up to $4,000 \mathrm{~km}$ apart for birds breeding in the same region and each subpopulation visiting up to 28 countries (44 in total). Additionally, Egyptian 
Vultures exhibited a high level of variability at the subpopulation level and flexibility at the individual level in basic migration parameters. Subpopulations differed significantly in travel distance and straightness of migratory movements, while differences in migration speed and duration differed as much between seasons and among individuals within subpopulations as between subpopulations. The total distances of the migrations completed by individuals from the Balkans and Caucasus were up to twice as long and less direct than those in Western Europe, and consequently were longer in duration, despite faster migration speeds. These differences appear to be largely attributable to more numerous and wider geographic barriers (water bodies) along the eastern flyway. We also found that adult spring migrations to Western Europe and the Balkans were longer and slower than fall migrations. We encourage further research to assess the underlying mechanisms for these differences and the extent to which environmental change could affect Egyptian Vulture movement ecology and population trends.

Keywords: migration connectivity, Neophron percnopterus, conservation biology, movement ecology, satellite tracking, GPS, phenotypic plasticity

\section{INTRODUCTION}

Many migratory bird populations have undergone substantial declines, mainly as a consequence of widespread expansion of human infrastructures and activities, habitat alteration, direct persecution, and climate change (Bauer et al., 2018). Migration routes vary in habitat, landscape, and atmospheric characteristics, as well as resource availability and the prevalence of threats, all of which influence migratory behavior (Mandel et al., 2011; Trierweiler et al., 2014) and survival rates (Strandberg et al., 2010; Klaassen et al., 2014). Migratory birds provide many valuable ecosystem services (Whelan et al., 2015), and population reductions that are caused by detrimental effects that occur anywhere along the flyway may have ecosystem consequences across continents (Buechley et al., 2018b). Disentangling individual- and population-level variation in migratory movements is therefore essential to understand what factors influence migrations and to predict how different species and subpopulations might respond to environmental changes (Trierweiler et al., 2014; Bauer et al., 2018).

To gain a more complete understanding of migratory systems it is valuable to evaluate variation in migratory patterns within and among individuals and subpopulations and to produce continental-scale maps of flyways and migratory networks (Trierweiler et al., 2014; Bauer et al., 2018). Two types of migratory patterns are frequently used to compare migratory populations: we refer to "migratory performance" as all metrics relating to the timing, duration, distance and straightness of all migratory journeys, and to "migratory connectivity" as the metric that quantifies the spatial proximity at which individuals migrating from the same breeding origin spend the non-breeding season (Webster et al., 2002; Cohen et al., 2018). The study of long-distance migration has benefitted from a rapid growth in individual-based tracking data with increasing spatial and temporal resolution, enabling more detailed investigation of variability and flexibility of migratory movements (López-López,
2016). Large soaring birds have been the subjects of many tracking studies, partly because their large size enabled the attachment of transmitters since early technical development (Shamoun-Baranes et al., 2003; Alarcón and Lambertucci, 2018; Sergio et al., 2019). However, while migratory patterns have been assessed for individuals from the same or proximate populations (Sergio et al., 2014; Vardanis et al., 2016; Schlaich et al., 2017; Vansteelant et al., 2017), and migratory connectivity has been evaluated for some raptor species (Martell et al., 2014; Trierweiler et al., 2014; Finch et al., 2017), relatively few studies have analyzed these patterns across large portions of a species' distribution (Mandel et al., 2011; Dodge et al., 2014; Monti et al., 2018).

We compiled a large telemetry dataset on the Egyptian Vulture Neophron percnopterus to analyze spatial and temporal variability of migratory movements within and among individuals and subpopulations. The Egyptian Vulture is distributed across southern Europe, central and southern Asia, the Middle East, and Africa, and is listed as globally Endangered due to significant population declines caused by multiple anthropogenic threats such as poisoning, and power infrastructure collisions and electrocutions (Botha et al., 2017; BirdLife International, 2019; Safford et al., 2019). The majority of individuals from northern breeding populations are long-distance migrants that overwinter in sub-Saharan Africa and the Arabian Peninsula, with juveniles often remaining in the winter range for more than a year after their first migration (López-López et al., 2014; Oppel et al., 2015; Buechley et al., 2018b). Migratory Egyptian Vultures also overwinter in regions where non-migratory breeding populations occur (BirdLife International, 2019). As soaring migrants, Egyptian Vultures rely on thermal and orographic lift (Agostini et al., 2015), and so their migratory routes are largely shaped by geographic features, particularly the avoidance of water crossings (García-Ripollés et al., 2010; Buechley et al., 2018b). As a result, individuals in Eastern Europe and Western Asia that migrate along the Red Sea Flyway pass through up to four bottlenecks in order to avoid water bodies (Buechley et al., 2018b), compared 
to individuals from Western Europe (e.g., France and the Iberian Peninsula) which only cross one major bottleneck at the Strait of Gibraltar (López-López et al., 2014). Although the migratory performance from eastern (Buechley et al., 2018b) and western populations (Meyburg et al., 2004; Vidal-Mateo et al., 2016) have been investigated separately, there has never been a comparative analysis of the migratory performance of Egyptian Vultures across the majority of the species' geographical range.

In this paper, we investigate migratory connectivity and variation in individual migratory performance within and among subpopulations from Western Europe, the Balkans, the Middle East, and the Caucasus Region of Western Asia. We examined (1) whether Egyptian Vultures exhibit strong or weak migratory connectivity within and among subpopulations; and (2) whether migratory performance and variability differ between subpopulations and season, while accounting for ontogenetic improvements by comparing performance among age classes (Sergio et al., 2014). Based on geography and the generalist habitat preferences of Egyptian Vultures, we predicted that migratory connectivity would be relatively low because while Egyptian Vulture movements are constrained by bottlenecks during migration, their winter distribution in the Sahel region of Africa is less constrained by geographic barriers (Finch et al., 2017). We further predicted that the distance and duration of migrations would be greatest for the Balkans subpopulation which has to negotiate several large water bodies, while it would be shorter for the Middle Eastern, Caucasian and Western European subpopulations, which only have to negotiate the Red Sea or the Strait of Gibraltar, respectively. We predicted better migratory performance and earlier spring departure in adults compared to younger individuals, due to individual improvements with increasing age (Sergio et al., 2017). Our findings contribute to general migration ecology theory and provide valuable comparisons for further investigations into why Egyptian Vulture populations have declined more rapidly in eastern Europe (Velevski et al., 2015) than in western Europe (Garcia-Ripolles and Lopez-Lopez, 2006).

\section{MATERIALS AND METHODS}

\section{Origins and Acquisition of Tracking Data}

Between 2007 and 2018, 94 Egyptian Vultures were fitted with transmitters in 11 different research projects (López-López et al., 2014; Buechley et al., 2018b; Caucanas et al., 2018), with deployments in Albania (2); Armenia (3); Bulgaria (23); Djibouti (1); Ethiopia (2); France (3); Greece (9); Israel (3); North Macedonia (3); Portugal (5); Russia (4); Spain (26); and Turkey (10). The ranges of tagged individuals extended across $>4,000$ longitudinal kilometers from the Iberian Peninsula in western Europe to the Caucasus Region in western Asia, and $\sim 4,000$ latitudinal kilometers from southern Europe to subSaharan Africa. This range covers $\sim 70 \%$ of the species' current global distribution and almost the entire wintering range in Sub-Saharan Africa. We classified four distinct subpopulations based on geographically distinct breeding ranges separated by long distances that inhibit demographic exchanges between subpopulations (Lieury et al., 2015): Western Europe (including birds summering in Portugal, Spain, and southern France); Balkans (Albania, Bulgaria, Greece and North Macedonia); Middle East (Israel); and Caucasus (northeastern Turkey, Armenia, Georgia, Azerbaijan, northwestern Iran, and Dagestan Province of Russia). All transmitters weighed $24-45 \mathrm{~g},<3 \%$ of body mass, which is below the recommended limits to avoid adverse effects; (Bodey et al., 2018) and were attached using backpack or leg-loop harness systems (Mallory and Gilbert, 2008; Sergio et al., 2015). GPS fixes and associated data were acquired at temporal resolutions ranging from one location per minute to one location every $2 \mathrm{~h}$ with dormancy periods during night, and with GPS positional accuracy of $\pm 18 \mathrm{~m}$. Individuals' age at deployment and age at the start of each separate migration were estimated in calendar years, based on known plumage traits of different age classes, with juveniles classed as in the first calendar year, immatures as second to fifth calendar year and adults classed as sixth calendar year or older (Clark and Schmitt, 1998). Four wild-origin adults from the Balkans $(n=2)$, Western Europe $(n=1)$, and Middle East $(n=1)$ subpopulations were released with transmitters after short periods of rehabilitation (Supplementary Table 2), but these individuals did not behave unusually compared to other individuals in their subpopulations. Capture and tagging procedures were carried out in accordance with the recommendations and regulations of each country of deployment.

\section{Data Processing and Delineation of Migration Periods}

Tracking data from each project were uploaded to the online repository movebank.org (Wikelski and Kays, 2019). Erroneous GPS fixes were removed using general purpose data filters (Douglas et al., 2012), with maximum plausible average speed set to $25 \mathrm{~ms}^{-1}$ and the error radius set to $30 \mathrm{~m}$. To standardize the temporal resolution of the data, we censored the data to include only the first location from each individual every day. For each individual and season (fall, spring), net squared displacement (NSD) was calculated using the adehabitatLT package (Calenge, 2006) in R statistical software (R Core Team, 2018). Plots of NSD over time for each individual and season were visually inspected to censor data from any seasons where an individual did not migrate (i.e., juveniles and immatures that stayed in Africa) or where a migration was not completed (Bunnefeld et al., 2011). We then calculated start and end dates of each individual migration by fitting non-linear models to plots of NSD over time, using the "disperser" model in the migrateR package (Bunnefeld et al., 2011; Spitz et al., 2017; Buechley et al., 2018b). These estimates were visually verified and manually refined. We identified the point at which an individual first initiated a migration as the first point at which NSD continuously increased away from the summer or winter range (Figure S1). We defined the end of migration as the first point at which NSD values plateaued upon reaching the winter or summer range (López-López et al., 2014; Buechley et al., 2018b). For all further analyses, only data from completed migration trajectories were used. The final dataset after processing consisted of 188 complete migrations (71 spring, 117 fall; Figure 1) by 60 individuals (24 tagged as 


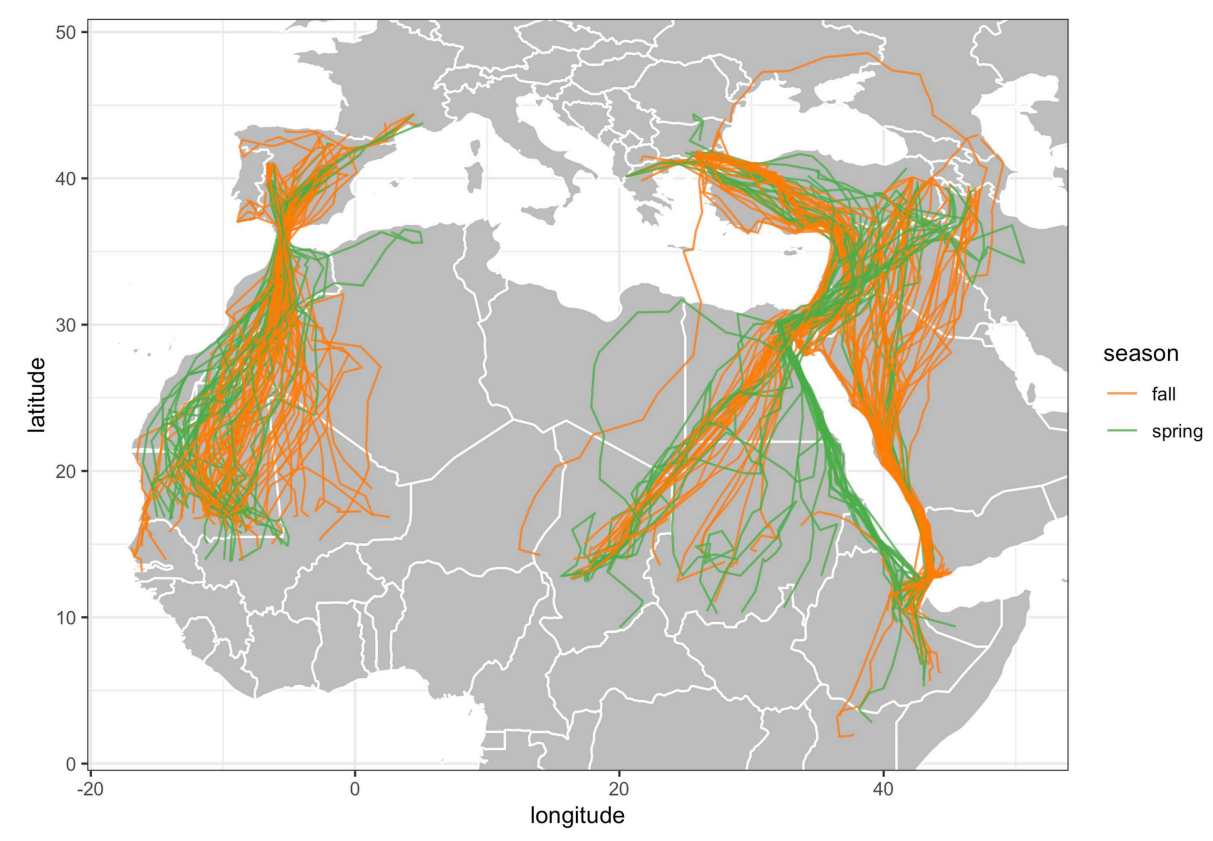

FIGURE 1 | Tracks of all 188 completed migrations of 60 individual Egyptian Vultures in both spring $(n=71)$ and fall $(n=117)$.

juveniles, 8 tagged as immatures and 28 tagged as adults). Of the completed migrations, 24 were completed by juveniles, 36 by immatures and 128 by adults, with the age at subsequent migrations adjusted according to the age at deployment (Table 1; Supplementary Tables 1, 2).

\section{Migratory Connectivity}

Migratory connectivity was quantified following methods described by Trierweiler et al. (2014), whereby the summer and winter range longitudes, identified as the first and last point of the first migration trajectory of each individual, were tested for correlations to assess for connectivity between and among subpopulations. Because the wintering range of Egyptian Vultures extends across most of the African Sahel, we did not use estimates of migratory connectivity that require the a priori definition of discrete geographic areas (Cohen et al., 2018). Instead, the strength of migratory connectivity was assessed using Mantel tests as described by Ambrosini et al. (2009) using the ade4 package (Dray and Dufour, 2007) in R statistical software (R Core Team, 2018), in which the statistical significance of the Mantel correlation coefficient was determined by 9,999 random permutations (Trierweiler et al., 2014). Mantel correlation coefficients correspond to simple Pearson product moment correlation coefficients between pairwise interindividual distance matrices constructed between start and end points of individual migrations (Ambrosini et al., 2009). Values range from -1 to 1 , with higher values indicating higher migratory connectivity (i.e., low levels of overlap in winter ranges of individuals from different subpopulations). These analyses were performed separately for spring and fall migrations, across all individuals and within each subpopulation. Fall and spring connectivity were analyzed separately because, in contrast to most small landbird species for which connectivity tends to be analyzed using single winter range locations (McKinnon and Love, 2018), Egyptian Vultures often move extensively in winter (López-López et al., 2014). In addition, many of the birds tracked in this study were young birds that dispersed widely in breeding and non-breeding areas, and migrations therefore did not originate from the same location where the previous migration of the same individual terminated.

\section{Individual-Level Migration Parameters}

Migration parameters were extracted for all complete migration trajectories using the amt package (Signer et al., 2019), following procedures previously described by Abrahms et al. (2017) and Buechley et al. (2018b): start and end dates (calendar and Julian days); start and end latitudes and longitudes; migration duration (days); direct distance (Euclidean) between start and end points $(\mathrm{km})$; cumulative distance (Euclidean) between start and end points, calculated as the sum of distances between each location in a migration $(\mathrm{km})$; migration straightness (direct distance/cumulative distance); and migration speed (cumulative distance/migration duration). We further summarized the above migrations by subpopulation (Western Europe, Balkans, Middle East, Caucasus), age class (juvenile, immature, adult), and season (spring, fall).

\section{Migratory Flexibility and Repeatability}

A Generalized Linear Mixed Model (GLMM) approach was used to examine which factors accounted for the most variability in migration parameters. We used the migration parameters described above as dependent variables, and entered subpopulation (Western Europe; Balkans; or Caucasus), season 
TABLE 1 | Median and range of migration parameters by season, age class at start of migration (Juv. $=$ hatch year; Imm. = 2nd -5 th calendar year; Ad. $=6$ th calendar year and older) and subpopulation.

\begin{tabular}{|c|c|c|c|c|c|c|c|}
\hline \multirow[b]{2}{*}{ Migration parameter } & \multirow[b]{2}{*}{ Age } & \multicolumn{2}{|c|}{ Western Europe } & \multicolumn{2}{|c|}{ Balkans } & \multicolumn{2}{|c|}{ Caucasus } \\
\hline & & Fall & Spring & Fall & Spring & Fall & Spring \\
\hline \multirow{3}{*}{$\begin{array}{l}\text { Number of completed } \\
\text { migrations ( } n)\end{array}$} & Juv. & 11 & 0 & 9 & 0 & 2 & 0 \\
\hline & Imm. & 5 & 3 & 4 & 7 & 11 & 6 \\
\hline & Ad. & 38 & 29 & 17 & 13 & 17 & 13 \\
\hline \multirow[t]{3}{*}{ Start date } & Juv. & 09-Sep (13-Aug-09-Oct) & - & 12-Sep (07-Sep-22-Sep) & - & 21-Sep (17-Sep-25-Sep) & - \\
\hline & Imm. & 15-Sep (02-Sep-23-Sep) & 20-Mar (19-Mar-03-Apr) & 19-Aug (31-Jul-28-Aug) & 30-Apr (19-Mar-05-May) & 09-Sep (11-Sep-30-Oct) & 18-Apr (16-Mar-29-May) \\
\hline & Ad. & 08-Sep (20-Jul-27-Sep) & 26-Feb (04-Feb-10-Mar) & 11-Sep (12-Aug-26-Sep) & 08-Mar (02-Jan-07-Apr) & 18-Sep (31-Jul-07-Oct) & 22-Mar (29-Jan-15-Apr) \\
\hline \multirow[t]{3}{*}{ End date } & Juv. & 09-Oct (17-Sep-22-Nov) & - & 16-Oct (27-Sep-13-Nov) & - & 12-Oct (04-Oct-20-Oct) & - \\
\hline & Imm. & 30-Sep (23-Sep-14-Oct) & 19-Apr (02-Apr-06-May) & 30-Sep (27-Sep-19-Oct) & 01-Jun (11-May-27-Jun) & 29-Sep (11-Sep-30-Oct) & 12-Jun (11-May-20-Jun) \\
\hline & Ad. & 22-Sep (15-Aug-17-Oct) & 17-Mar (26-Feb-07-Apr) & 02-Oct (05-Sep-16-Oct) & 06-Apr (18-Mar-01-May) & 04-Oct (17-Sep-04-Nov) & 10-Apr (23-Mar-30-Apr) \\
\hline \multirow[t]{3}{*}{ Duration (days) } & Juv. & $34(14-77)$ & - & 27 (18-60) & - & $20(16-25)$ & - \\
\hline & Imm. & $20(15-21)$ & $16(13-48)$ & $48(35-64)$ & $45(15-58)$ & $19(12-41)$ & $28(21-83)$ \\
\hline & Ad. & $14(9-26)$ & $21(13-33)$ & $21(11-65)$ & $31(18-90)$ & $18(12-61)$ & $18(15-67)$ \\
\hline \multirow[t]{3}{*}{ Direct distance $(\mathrm{km})$} & Juv. & $3,021(2,641-3,370)$ & - & $3,404(3,237-4,136)$ & - & $3,424(2,789-4,058)$ & - \\
\hline & Imm. & $2,793(2,736-3,030)$ & $2,871(2,537-3,029)$ & $4,056(3,345-4,584)$ & $3,829(3,582-3,936)$ & 4,012 (3,595-5,452) & $4,177(3,406-4,910)$ \\
\hline & Ad. & $2,730(2,267-3,368)$ & $2,819(2,472-3,333)$ & 3,303 (2,948-5,093) & $3,547(3,219-4,981)$ & $4,150(3,728-5,062)$ & $4,021(3,723-5,041)$ \\
\hline \multirow[t]{3}{*}{ Cumulative distance $(\mathrm{km})$} & Juv. & $3,792(3,129-4,724)$ & - & $5,281(4,147-6,856)$ & - & $3,830(2,986-4,675)$ & - \\
\hline & Imm. & $3,091(2,995-3,264)$ & $3,700(2,820-5,679)$ & $7,017(5,649-7,713)$ & $7,050(4,964-8,279)$ & $4,552(4,064-6,575)$ & $6,210(4,606-10,983)$ \\
\hline & Ad. & $3,097(2,415-3,779)$ & $3,265(2,846-4,657)$ & $5,404(4,479-7,213)$ & $5,911(4,848-7,225)$ & $4,611(4,042-6,217)$ & $5,177(4,351-5,553)$ \\
\hline \multirow[t]{3}{*}{ Speed $\left(\mathrm{km} \mathrm{d}^{-1}\right)$} & Juv. & $113(61-250)$ & & $183(105-251)$ & & $187(187-187)$ & - \\
\hline & Imm. & $155(147-210)$ & $217(118-231)$ & $138(121-183)$ & $184(133-331)$ & 241 (129-364) & $190(78-266)$ \\
\hline & Ad. & $217(144-321)$ & $161(117-242)$ & $269(111-407)$ & $198(80-286)$ & $286(85-384)$ & $273(73-327)$ \\
\hline \multirow[t]{3}{*}{ Straightness } & Juv. & $0.790(0.694-0.952)$ & - & $0.645(0.528-0.819)$ & - & $0.901(0.868-0.934)$ & - \\
\hline & $\mathrm{Imm}$ & $0.926(0.897-0.933)$ & $0.819(0.506-0.900)$ & $0.624(0.438-0.692)$ & $0.508(0.444-0.793)$ & $0.847(0.791-0.969)$ & 0.709 (0.383-0.778) \\
\hline & Ad. & $0.905(0.772-0.982)$ & $0.875(0.642-0.945)$ & $0.631(0.528-0.925)$ & $0.591(0.469-0.899)$ & $0.924(0.600-0.977)$ & $0.840(0.706-0.941)$ \\
\hline
\end{tabular}

Migration start and end are the days on which migration initiated and concluded. Direct distance $(\mathrm{km})$ is the Euclidean distance between summer and winter ranges, while cumulative distance is the sum of distances between each successive point in the migration trajectory. Migration duration (days) is the number of days spent on migration, and migration speed (km $\mathrm{d}^{-1}$ ) is the cumulative migration distance divided by the migration duration. Straightness is the ratio between the direct and cumulative distance. Only parameters from complete migration trajectories were included. 
(spring or fall) and age at migration (in calendar years as a sixlevel factor) as fixed effects, and individual nested within year of migration as random intercept to account for non-independence in migration parameters within years and individuals. Overall, we evaluated eight different candidate models for each migration parameter: a null model and seven models including the three fixed effects and all potential additive combinations as independent predictors. We did not include the three individuals from the Middle East subpopulation in the comparative analysis of migration parameters among subpopulations because the small sample size prevented meaningful comparisons.

GLMMs were fitted with Gaussian distribution and identity link using the lme4 package in $\mathrm{R}$ (Bates et al., 2015), and we considered the model with the lowest Akaike Information Criterion (AIC) as the most parsimonious and present parameter estimates from that model. Two of the migration parameters (direct distance and cumulative distance) were log transformed to meet the assumptions of GLMMs (Zuur et al., 2009). Models were compared using the maximum likelihood estimation and were validated by checking for homoscedasticity and normality of the residuals. To that end, relevant model diagnostic graphs were computed (residuals against fitted values, residuals against each explanatory variable, histogram of residuals and normality Q-Q plots). We computed marginal and conditional $\mathrm{R}^{2}$ following Nakagawa and Schielzeth (2013) using the piecewiseSEM R package (Lefcheck, 2016) to assess the overall explanatory power of the model (i.e., for fixed and random effects separately). All computations were performed in $\mathrm{R}$ version 3.5.1 (R Core Team, 2018).

To quantify the variation in migration parameters among populations, we estimated repeatability of migration parameters as an estimate of the fraction of total variance (sum of betweenand within-population variation) that scales from 0 to 1 , with 0 indicating that all the variance is within a population, and 1 indicating that all the variance is between populations (Bell et al., 2009; Nakagawa and Schielzeth, 2010). Repeatability was estimated with the $\mathrm{R}$ package $r p t R$ (Stoffel et al., 2017), using the fixed factors supported by the above GLMM analysis to account for seasonal or age variation in the data. We concluded that there was significant repeatability of migration parameters within subpopulations if $95 \%$ confidence intervals of repeatability estimates did not overlap zero.

Additionally, we calculated the width of the migration corridor for each subpopulation in order to provide a measure of route flexibility (López-López et al., 2014). The width of the migration corridor was measured by computing the linear distance of the maximum longitudinal separation (i.e., East-West) of individual tracks at $5^{\circ}$ latitude intervals from $15^{\circ} \mathrm{N}$ to $40^{\circ} \mathrm{N}$, encompassing the full latitudinal range cover by both fall and spring migrations. The width of migration corridors was computed for the complete dataset of migration tracks and also for spring and fall seasons, separately. Computations were done in ArcMap 10.0 (ESRI, 2014) using the World Latitude and Longitude $1 \times 1$ degree Grid (available at https://www.arcgis.com/home/item. html?id=f11bcdc5d484400fa926dcce68de3df7). We compared the width of the migration corridors between seasons and subpopulations using a Mann Whitney and a Kruskal-Wallis test, respectively.

\section{RESULTS}

\section{Migratory Connectivity}

There was high correlation between summer and winter longitudes and high Mantel test scores (>0.88) across all individuals, indicating very high migratory connectivity at the species level (Table 2; Figure 2). However, within each subpopulation, insignificant correlations and negative Mantel scores indicated very low migratory connectivity. The Balkans subpopulation exhibited the widest range of winter longitudes, overlapping with Middle East and Caucasus subpopulations. Migration routes entered 44 different countries, with the Balkan subpopulation entering the most (28 countries), followed by Caucasus (20), Western Europe (12) and Middle East (6; Figure 1). Complete fall migrations finished in four countries for the Balkans (Chad =16/30; Ethiopia $=7 / 30$; Sudan $=5 / 30$; Yemen $=2 / 30$ migrations) and Western Europe (Mauritania $=39 / 54$; Mali $=11 / 54$; Senegal $=3 / 54$; The Gambia $=1 / 54$ migrations), with Caucasus fall migrations mainly finishing in Ethiopia (23/30 migrations) and the three fall migrations from the Middle East ending in Chad (1) and Sudan (2), with spring departures following similar patterns (Figure 2).

\section{Individual-Level Migration Parameters}

The Balkan subpopulation migrations were the least straight and longest in terms of duration and total cumulative distance, whereas those completed by individuals from the Caucasus subpopulation were longest in terms of direct distance (Table 1; Figure 3). Migrations completed by individuals from Western Europe were the straightest and shortest (Table 1; Figure 3). Spring migrations were longest in duration for adults from the Balkans subpopulation, and started later for both the Balkans (median start date for adults $=8$ th March; median duration for adults $=31$ days) and Caucasus (median start date for adults $=22$ nd March; median duration for adults $=18$ days) subpopulations, compared to Western Europe (median start date for adults $=26$ th February; median duration for adults $=21$ days Table 1; Figure 3). Fall migrations started on similar dates (between 20th July and 9th October) among subpopulations, but lasted, on average, 6 and 8 days longer for individuals from the Balkans compared to those from the Caucasus and Western Europe, respectively. Migration speeds were fastest for the Caucasus, then Balkans, with individuals from Western Europe migrating more slowly. Adults from all subpopulations migrated slower in spring than fall, covering on average 71,13 , or $56 \mathrm{~km}$ less per day when migrating to the Balkans, Caucasus, or Western Europe, respectively (Table 1; Figure 3). Exploratory analyses confirmed that multi-day stopovers occurred very rarely among all subpopulations (López-López et al., 2014; Buechley et al., 2018b).

At the subpopulation level, adults from Western Europe demonstrated higher migration efficiency than juveniles, traveling faster along straighter and shorter (in distance and duration) migration routes. In the Balkans, straightness of 
TABLE 2 | Mantel correlation coefficients of migratory connectivity and R-squared correlation coefficients between longitudes of migration start and end locations from the first completed migration of each individual in each season.

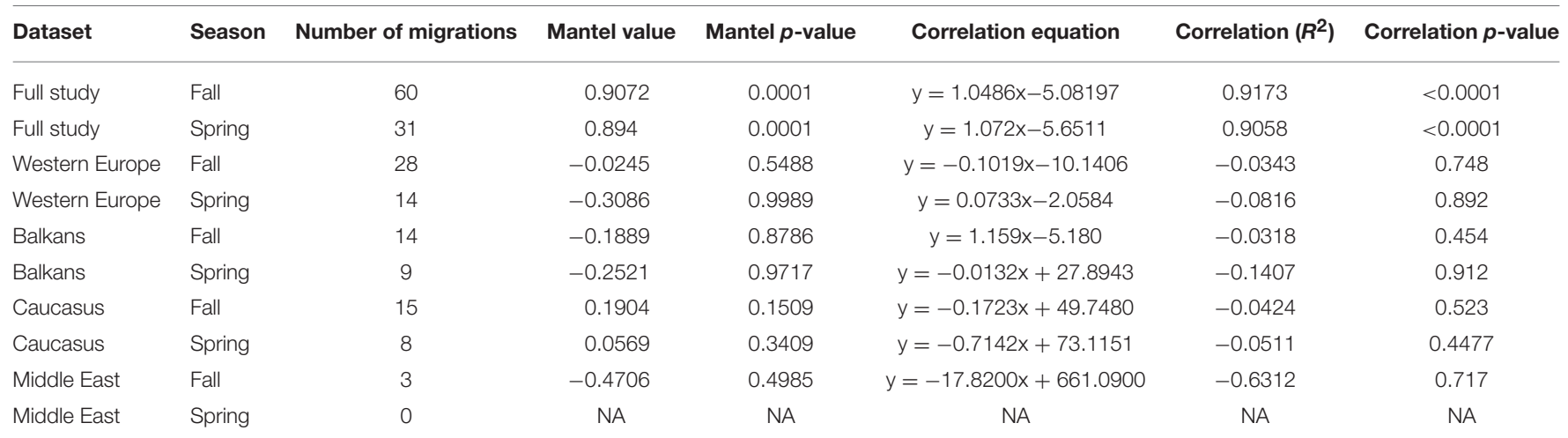

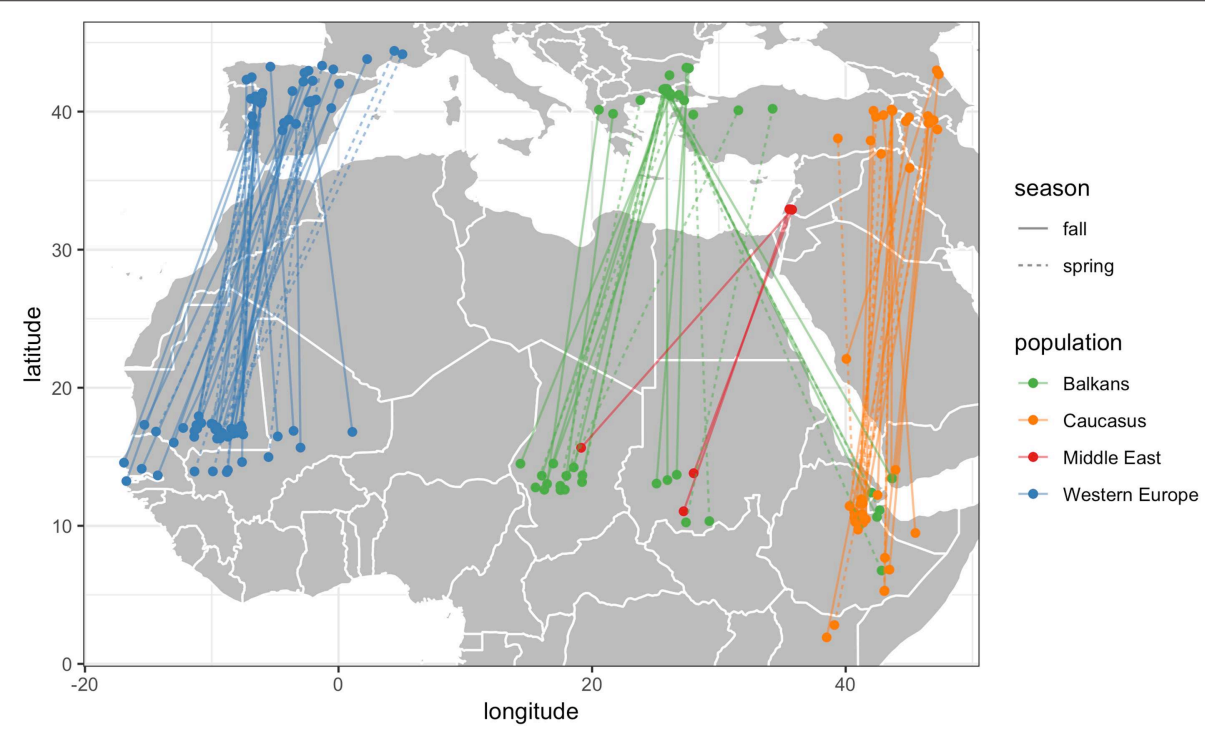

FIGURE 2 | Start and end locations of the first complete spring and fall migrations of 60 individual Egyptian Vultures used to assess migratory connectivity within and among four subpopulations.

migration routes did not differ among age classes, but adults migrated more quickly (Table 1; Figure 3). Adults from the Caucasus subpopulation appeared to travel faster and longer distances than juveniles in fall, but this comparison lacked power because of the small sample size of complete juvenile migrations (Table 1; Figure 3). Immature individuals from all subpopulations started spring migration later than adults, with the greatest difference observed in the Balkan subpopulation (difference between adult and immature median start date $=$ 53 days; Table 1; Figure 3). Although fall departure dates were similar among age classes in Western Europe and the Caucasus, immatures departed earlier than adults and juveniles in the Balkans. Overall, adults and immatures tended to complete fall migration earlier than juveniles across all subpopulations.

The two fall migrations completed by juveniles from the Middle East subpopulation were comparable to juvenile fall migrations in Western Europe in terms of cumulative distance $[$ median $(\min -\max )=3297(2,987-3,607) \mathrm{km}]$ and straightness
[0.809 (0.731-0.887)], but were faster [speed $=200(150-$ 249) $\mathrm{km} \mathrm{d}^{-1}$ ] and shorter in duration [18 (12-24) days)] and direct distance $(2,642(2,635-2,649) \mathrm{km}]$. The fall migration parameters for the single adult individual from the Middle East were similar to the two juveniles (cumulative distance $=3,600 \mathrm{~km}$; direct distance $=2,999 \mathrm{~km}$; straightness $=0.83$ ). The fall departure dates for the three Middle East migrations were similar to the other subpopulations (30th August (29th August-19th September).

\section{Migratory Flexibility and Repeatability}

The most parsimonious models for all migratory parameters included subpopulation as a factor, indicating that there were differences among these geographic subpopulations in migration distance, straightness, duration, start and end dates, and migration speed (Supplementary Table 3). Start and end dates, duration and speed also varied among seasons and age groups (Table 3). Cumulative distance and straightness values only 

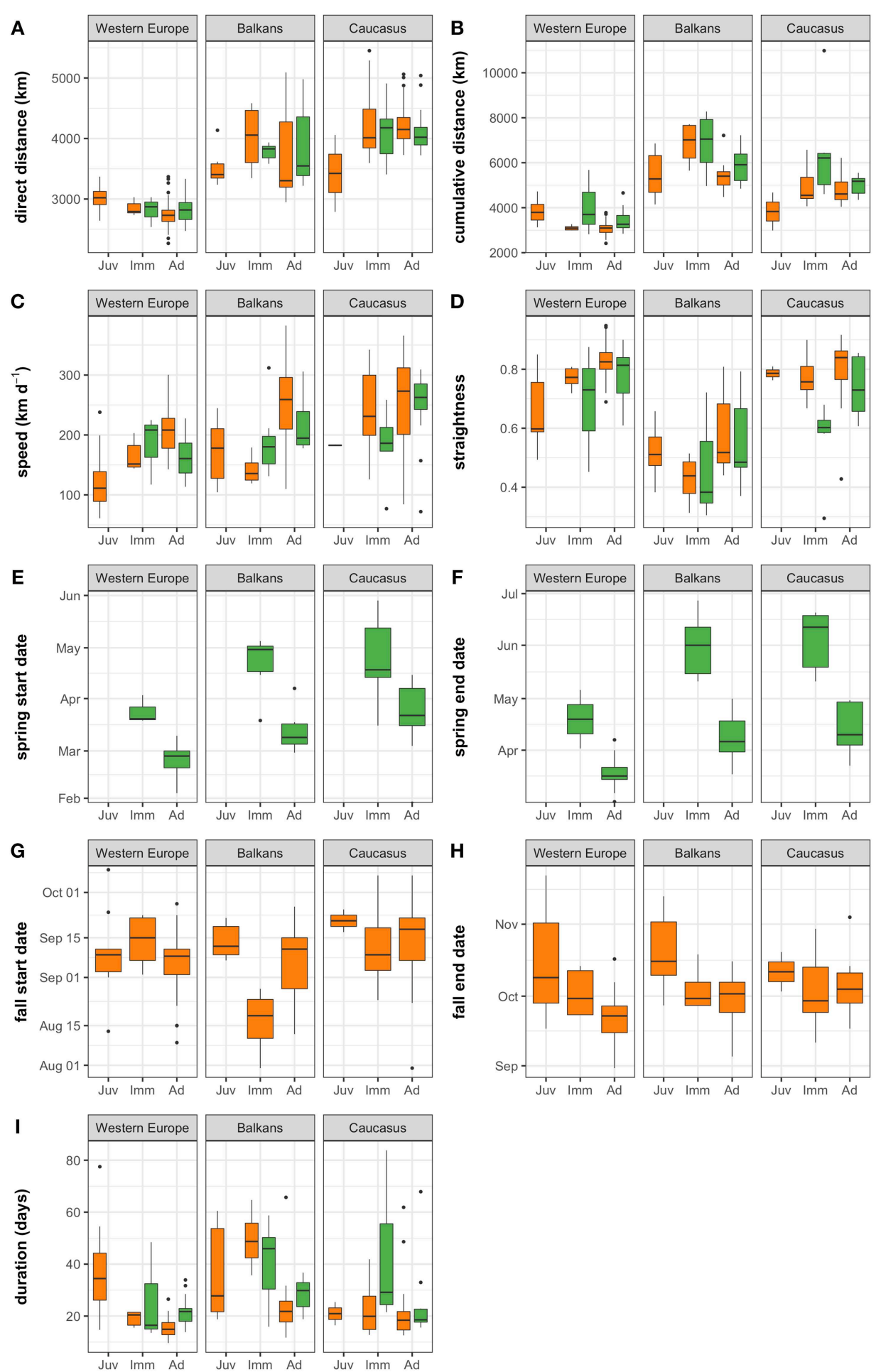

$\biguplus_{\text {fall }}$ spring

FIGURE 3 | Boxplots showing median and inter-quartile range of Egyptian Vulture migration parameters by season, age class (Juv. = hatch year; Imm. $=2 \mathrm{nd}-5$ th calendar year; Ad. = 6th calendar year and older), and subpopulation. (A) Direct distance is the distance between summer and winter ranges; (B) cumulative distance is the summed distances between each successive point in the migration trajectory; (C) migration speed $\left(\mathrm{km} \mathrm{d}^{-1}\right)$ is the cumulative migration distance divided by the migration duration; (D) straightness is the ratio between the direct and cumulative distance; migration start (E,G) and end $\mathbf{( F , H )}$ are the days on which migration initiated and concluded; and (I) migration duration is the number of days spent on migration. Orange and green bars indicate fall and spring migrations, respectively. Only parameters from complete migration trajectories were included (refer to Supplementary Table $\mathbf{1}$ for sample sizes). 
varied among subpopulations and seasons. While the models for start and end dates, cumulative distance and direct distance explained most $(>80 \%)$ of the variability in the data, variation in speed and travel duration was poorly captured $(<60 \%)$ by our three predictor variables (Table 3 ).

There was high repeatability $(r>0.5$; Table 3$)$ within subpopulations in the three route-related migration parameters, cumulative travel distance, direct distance, and straightness. This confirmed that there was more variation in these parameters between than within each subpopulation. We found no significant repeatability for duration $(r=0.120$; 95\% CI $=0-0.356$; Table 3) or speed ( $r=0.270 ; 95 \%$ CI $=0-0.603)$, indicating that there is large variability within each subpopulation.

The mean width of seasonal migration corridors for each subpopulation between $15^{\circ} \mathrm{N}$ and $40^{\circ} \mathrm{N}$ ranged from $802 \pm$ $598 \mathrm{~km}$ at $35^{\circ} \mathrm{N}$ to $1,429 \pm 1,041 \mathrm{~km}$ at $20^{\circ} \mathrm{N}$. The maximum East-West separation of individual routes was recorded between $15^{\circ}$ and $25^{\circ} \mathrm{N}$, both in autumn and spring migrations (Table 4), which approximately coincides with the latitudes of the Sahara and Arabian Deserts. Significant differences in the width of migration corridors were observed among subpopulations (Kruskal-Wallis test: $H_{2,36}=13.84, p<0.001$ ), with the Balkan subpopulation exhibiting an average migration corridor width 2.59 and 4.39 times larger than Western Europe and Caucasus subpopulations, respectively (mean \pm SD corridor width for Balkans $=1,970 \pm 859 \mathrm{~km}$; Western Europe $=$ $818 \pm 446 \mathrm{~km}$; Caucasus $=611 \pm 287 \mathrm{~km}$ ). No significant differences in the width of migration corridors were observed between seasons when data from different latitudes were pooled together (Mann-Whitney test: $U=164.00, Z=0.363, p=$ 0.732). However, for the Western Europe subpopulation, the fall migration corridors at $15^{\circ} \mathrm{N}$ and $20^{\circ} \mathrm{N}$ (i.e., the Sahel and southern Sahara) were 1.68 and 2.02 times wider, respectively, than the spring migration corridors at the same latitudes, whereas the opposite was observed for the Caucasus subpopulation, with the spring migration corridors being $>4$ times larger than the fall migration corridors at those latitudes (Table 4). For the Balkans subpopulation, the much wider fall migration corridors at $35^{\circ} \mathrm{N}$ and $40^{\circ} \mathrm{N}$ were due to the single journeys of extreme easterly and westerly routes by a juvenile and an immature. Similarly, the wide spring migration corridor for the Western Europe subpopulation at $35^{\circ} \mathrm{N}$ (i.e., south of the Mediterranean) was due to eastwards movements of a single immature individual, with similar widths recorded in fall $(104 \mathrm{~km})$ compared to spring $(154 \mathrm{~km})$ when that outlier was removed.

\section{DISCUSSION}

Several studies have described the migration of Egyptian Vultures along the western European-West African flyway (GarcíaRipollés et al., 2010; López-López et al., 2014) and along the Eurasian-East African flyway (Oppel et al., 2015; Buechley et al., 2018a,b). Our synthesis highlights that there is very little overlap in the wintering destinations between the western and eastern subpopulations of Egyptian Vultures in Europe, but that individuals from the Balkans, the Middle East and Central Asia often converge around the Horn of Africa, where major concentrations occur during migration (Welch and Welch, 1988; Buechley et al., 2018b) and in winter (Arkumarev et al., 2014). The different destinations and routes of the subpopulations also result in substantial differences in distance and duration of migrations, with birds from the Balkans performing the most convoluted and longest migrations, which can be twice as long as the relatively straight migratory routes of birds from Western Europe.

The results suggest that the key reason for the different migration distances is the presence of water barriers, which soaring raptors are generally reluctant to cross due to limited thermal uplift (Panuccio et al., 2012; Agostini et al., 2015). While the western population can cross the relatively short Strait of Gibraltar (Martín et al., 2016), birds from the Balkans tend to detour around the Mediterranean and the Red Sea (Oppel et al., 2015; Buechley et al., 2018b). Once these barriers have been negotiated, individuals may spread out, or travel along coastlines, depending on the geography and direction of travel. However, a more comprehensive assessment of the effects of other environmental conditions, such as wind (Vansteelant et al., 2017), thermal uplift (Duriez et al., 2018; Rotics et al., 2018) and human development (Tucker et al., 2018) is required to investigate the relative importance of these different factors in shaping migration routes for the different subpopulations.

\section{Migratory Connectivity}

We found a weak and insignificant Mantel correlation within subpopulations, indicating weak migratory connectivity at the subpopulation scale, as reported by Finch et al. (2017). However, we show that connectivity is relatively strong at the continental scale, with no overlap between the western and two eastern subpopulations during winter in Africa, and only moderate overlap in the Horn of Africa between the Balkan and Caucasian subpopulations (Trierweiler et al., 2014). High connectivity is uncommon for species with large non-breeding range spread (Finch et al., 2017), but our results indicate that even very widespread species such as the Egyptian Vulture can have reasonably strong migratory connectivity at large spatial scales (Trierweiler et al., 2014). Therefore, our results highlight that migratory connectivity is dependent on the spatial scale of analysis and that caution is required when assessing and interpreting connectivity for widespread species if comparisons are based on individuals from a relatively small or spatially biased portion of the species' range (Trierweiler et al., 2014; Finch et al., 2017; Cohen et al., 2018).

The population spread of wintering areas was greatest for the Balkan subpopulation, despite being the smallest of the subpopulations studied here (Velevski et al., 2015). The larger non-breeding range spread of the Balkan population may be caused by vultures bypassing the Mediterranean Sea on the eastern border and then bifurcating around the Red Sea, with some individuals continuing south through the Arabian Peninsula, while others traveled southwest via Egypt and across the Sahara. Conversely, both the Western Europe and Caucasus subpopulations are only constrained by bottlenecks at the 
TABLE 3 | Generalized Linear Mixed Model (GLMMs) results of the most parsimonious models fitted for migration parameters of Egyptian Vultures tracked by GPS telemetry across three continents. AICW indicates the weight of evidence for this model among eight candidate models.

\begin{tabular}{|c|c|c|c|c|c|}
\hline Dependent variable & Fixed effect(s) & $\mathbf{A I C}_{\mathrm{W}}$ & $R^{2}$ fixed effects & $\mathrm{R}^{2}$ random effects & Repeatability \\
\hline Direct distance & Subpopulation & 0.986 & 0.698 & 0.233 & $0.742(0.032-0.914)$ \\
\hline Cumulative distance & Subpopulation season & 0.984 & 0.725 & 0.097 & 0.709 (0.034-0.899) \\
\hline Straightness & Subpopulation season & 0.998 & 0.460 & 0.245 & $0.547(0.016-0.832)$ \\
\hline Duration & Subpopulation season age & 0.999 & 0.265 & 0.252 & $0.120(0.000-0.356)$ \\
\hline Start date & Subpopulation season age & 1.000 & 0.963 & 0.000 & $0.140(0.000-0.392)$ \\
\hline End date & Subpopulation season age & 1.000 & 0.965 & 0.000 & $0.238(0.000-0.567)$ \\
\hline Speed & Subpopulation season age & 1.000 & 0.333 & 0.177 & $0.270(0.000-0.603)$ \\
\hline
\end{tabular}

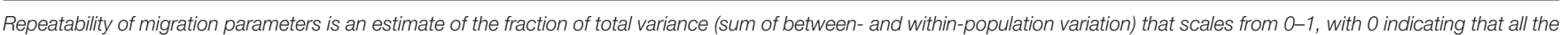
variance is within a population, and 1 indicating that all the variance is between populations.

TABLE 4 | Width $(\mathrm{km})$ of the migration corridor at $5^{\circ}$ latitude intervals for 60 Egyptian Vultures tracked by GPS telemetry across three continents.

\begin{tabular}{|c|c|c|c|c|c|c|c|c|c|c|c|c|}
\hline \multirow[b]{2}{*}{ Latitude } & \multicolumn{3}{|c|}{ Full study } & \multicolumn{3}{|c|}{ Western Europe } & \multicolumn{3}{|c|}{ Balkans } & \multicolumn{3}{|c|}{ Caucasus } \\
\hline & Total & Fall & Spring & Total & Fall & Spring & Total & Fall & Spring & Total & Fall & Spring \\
\hline 40 & 4,652 & 4,652 & 4,020 & 532 & 532 & 391 & 2,176 & $2,176^{\star}$ & $765^{\star}$ & 662 & 584 & NA \\
\hline 35 & 5,087 & 4,882 & 5,087 & 766 & $104^{*}$ & $766^{*}$ & 1,795 & $1,795^{\star}$ & $282^{*}$ & 1,075 & 870 & 995 \\
\hline 30 & 5,218 & 5,218 & 4,812 & 767 & 767 & 591 & 2,151 & 1,628 & 1,667 & 1,266 & 819 & 871 \\
\hline 25 & 5,776 & 5,532 & 5,510 & 1,546 & 1,296 & 1,149 & 2,372 & 1,890 & 2,083 & 934 & 577 & 662 \\
\hline 20 & 6,033 & 6,022 & 6,002 & 1,784 & $1,784^{\star}$ & $881^{*}$ & 2,784 & 2,784 & 2,354 & 626 & $143^{*}$ & $626^{\star}$ \\
\hline 15 & 6,453 & 6,453 & 5,810 & 1,225 & $979^{\star}$ & $582^{*}$ & 3,352 & 3,342 & 2,874 & 495 & $110^{*}$ & $460^{\star}$ \\
\hline 10 & 2,466 & 369 & 2,423 & NA & NA & NA & 2,387 & NA & 2,302 & 369 & 369 & 230 \\
\hline
\end{tabular}

Asterisks $\left(^{*}\right)$ indicate where spring and fall migration routes differed by at least a factor of two, indicating that either spring or fall migration is much more constrained.

Strait of Gibraltar and the Bab-el-Mandeb Strait, near their breeding and wintering ranges, respectively, which may reduce the range spread of these subpopulations. Longer migration distance and greater migratory spread have been associated with population declines of species that migrate using the AfroPalearctic flyway, possibly as a result of uneven distribution of anthropogenic threats associated with uneven human population growth and development (Patchett et al., 2018). Although further work is required to assess variability in mortality patterns and demographic effects among the different subpopulations, the longer migrations and greater migratory spread for the Balkans subpopulation could partially explain faster declining populations compared to the other subpopulations (Velevski et al., 2015).

\section{Migratory Flexibility}

We found relatively high repeatability within subpopulations for distance and for straightness of travel, but much lower repeatability for duration and speed. The variation in duration and speed may be the result of varying environmental conditions and stopover use during each migratory journey (Vansteelant et al., 2015; Kölzsch et al., 2016; Vardanis et al., 2016; Monti et al., 2018) and, although multi-day stopovers are rare in Egyptian Vultures (López-López et al., 2014; Buechley et al., 2018b), further detailed investigation of both aspects is required. Greater speed during spring migration than fall migration has been hypothesized to be the result of a heightened drive to arrive on breeding grounds, and has been recorded in many species of soaring migrants (Alerstam, 2003; Nilsson et al., 2013). Greater migration speed in spring can also be a consequence of greater wind assistance (Bauchinger and Klaassen, 2005; Kemp et al., 2010), although fitness costs of early arrival due to less favorable atmospheric conditions during migration have been recorded in some species (Rotics et al., 2018). However, just as for other species (Schmaljohann, 2018), our data suggest that adult Egyptian Vultures migrate faster in fall than spring, although this effect was less pronounced for the Caucasus subpopulation. However, the spring migration of birds from the Caucasus subpopulation was slightly longer in both duration and distance, as most birds migrated to the west of the Red Sea in spring and therefore traveled farther compared to fall migration east of the Red Sea (Buechley et al., 2018b), explaining the wider spring migration corridor at those latitudes and emphasizing the importance of water barriers in shaping the migratory movements for the species. In contrast, the spring migration corridor between the Sahel and Sahara for the Western Europe subpopulation was half the width of the fall corridor at the same latitudes, likely due to the selection of more westerly migration routes in response to wind conditions (Vidal-Mateo et al., 2016). There is ongoing debate about the relative importance of innate motivation and external factors (e.g., wind) in causing seasonal differences in migration speed (Lindström et al., 2019). Although we found marked differences in route choice between seasons, but inconsistent differences 
in performance, much more work is needed to determine how various innate and external factors contribute to the development of seasonal and population specific migration patterns, not only for Egyptian Vultures but all migratory species (Schmaljohann, 2018). Similar to other raptors, we also found some age-related differences in migration distance, duration, speed and timing (Sergio et al., 2014), with adults traveling faster along shorter routes, and departing earlier in spring, than younger birds (Monti et al., 2018), although the patterns were not consistent in all subpopulations. While our dataset did not allow a full assessment of changes in individual migratory performance with age (sensu Sergio et al., 2014), our findings are consistent with expectations that individual raptors must improve their migratory performance in early life to eventually be recruited into the breeding population (Sergio et al., 2017).

Although further work is required to assess the effects of environmental factors on migratory movements of Egyptian Vultures, the variability within and among each subpopulation indicates that they could potentially respond to short term changes in environmental conditions along their flyway which could eventually affect migration phenology (Both, 2010; Klaassen et al., 2014). However, the migration corridor for all subpopulations was widest over the Sahara desert, where conditions for soaring migrants may be harsh during extreme weather conditions (Strandberg et al., 2010; Vansteelant et al., 2017). Although juveniles and immature individuals may be particularly vulnerable during Sahara crossings, adults also demonstrate aberrant behaviors there, sometimes resulting in carry-over effects on breeding success (Strandberg et al., 2010). Our results show that the spring and fall migration corridors for the Balkans subpopulation are 1.81 and 1.46 times wider over the Sahara than for the Western Europe subpopulation, respectively (Table 4). Suboptimal route selection, possibly due to limited conspecific guidance because of recent rapid population declines (Velevski et al., 2015), may result in higher mortality rates of juvenile Egyptian Vultures from the Balkans during fall migration when they attempt fatal sea crossings (Oppel et al., 2015). Although the effects of different migration strategies and route selection on Egyptian Vulture survival require further investigation at the subpopulation level, our results suggest that individuals from the Balkans use migration routes that may expose them to a broader range of different threats and migration conditions than individuals from Western Europe or the Caucasus (Patchett et al., 2018).

\section{FUTURE DIRECTIONS}

This study provides the foundations for further investigation into the underlying causes of variation in migration strategies of Egyptian Vultures and the potential effects on individual survival and fitness, and ultimately population dynamics. We encourage future research to investigate the effects of environmental factors on migratory movements and to evaluate whether the different levels of anthropogenic threats encountered along the flyways used by different subpopulations could explain differences in population trends in breeding regions. A potential approach to resolve such differences would be more intensive study of resident populations of Egyptian Vultures in sub-Saharan Africa and the Middle East, and quantification of the trade-offs and benefits of migratory vs. resident lifestyles (Sanz-Aguilar et al., 2015). With recent tagging of Egyptian Vultures within wintering ranges (Buechley et al., 2018a; McGrady et al., 2018) this may soon be possible to explore in more detail, enabling a comprehensive comparison of movement strategies in relation to human activity (Tucker et al., 2018). Furthermore, although our dataset did not enable the investigation of the ontogeny of migration in Egyptian Vultures [e.g., Scott et al. (2014)], future analysis of movement data derived from individuals tracked from juvenile to breeding adult status will provide a clearer understanding of the development of migration strategies and the variation within and among individuals as they age. Finally, this study illustrates that broad-scale collaboration can contribute to overcoming one of the grand challenges of migration research by enabling the mapping of flyways at a continental scale (Bauer et al., 2018), with the ultimate aim of informing strategies to protect threatened species based on a sound understanding of their movement ecology (Fraser et al., 2018; Choi et al., 2019).

\section{DATA AVAILABILITY}

The data analyzed in this study were obtained from tracking projects listed in the Movebank database (https://www. movebank.org/). Requests to access these datasets should be directed to the contact persons and principal investigators listed for each individual Movebank project, with contact details available from the corresponding author.

\section{ETHICS STATEMENT}

All procedures were carried out in accordance with the recommendations and regulations of each country of deployment.

\section{AUTHOR CONTRIBUTIONS}

EB, PL-L, WP and SO conceived and designed the study, collected and collated data, performed the statistical analyses and led the writing of the manuscript. All other co-authors contributed to the conception of the individual tracking projects, acquisition of the data and writing of the manuscript.

\section{FUNDING}

Balkans and Caucasus data: This work was financially supported by the LIFE+ projects LIFE10 NAT/BG/000152 and LIFE 16 NAT/BG/000874 funded by the European Union and cofunded by the AG Leventis Foundation and MAVA, the US National Science Foundation, the Christensen Fund, National Geographic Society, the Whitley Fund for Nature, Faruk Yalçin Zoo and Kuzey Doga’s donors (in particular Bilge Bahar, Devrim Celal, Seha Işmen, Lin Lougheed, Burak Över, and Batubay Özkan). We are grateful to Turkey's Ministry of Forestry 
and Water Affairs General Directorate of Nature Conservation and National Parks and NorthStar Science and Technology for donating three transmitters each. State Nature Reserve Dagestanskiy and Russian Raptor Research and Conservation Network supported work in Dagestan. Western Europe data: deployments of transmitters in Portugal were funded by the EUfunded LIFE Rupis project (LIFE14 NAT/PT/00855); SALORO S.L.U. funded the deployment of transmitters in the Duero region of Spain; DREAL Nouvelle-Aquitaine-Fondation d'entreprises Barjane funded deployments in France; JE was supported by Basque government predoctoral grant (grant number: 569382696); GREFA (Grupo para la Rehabilitación de la Fauna Autóctona y su habitat)-Endangered Species Monitoring Project together with Poison Sentinels Project of WWF/Spain. The Migra Program of SEO/BirdLife (www.migraciondeaves.org/en/) deployed transmitters in collaboration with Fundación Iberdrola España, and were funded by La Rioja Regional Government in La Rioja, and Fundación Hazi and Diputación Foral de Gipuzkoa within the Interreg POCTEFA-ECOGYP project in Gipuzkoa.

\section{ACKNOWLEDGMENTS}

We dedicate the article to the memory of Michele Panuccio and his passion for and expertise in migration ecology. We also thank Michele and the other reviewers, Wouter Vansteelant and Tom Finch, for their positive and constructive comments which improved the article.

Balkans and Caucasia data: We thank our collaborators including Kuzey Doga Society (Turkey), Igdir Directorate of Nature Conservation and National Parks (Turkey), American University of Armenia, Ethiopia Wildlife Conservation Authority, Ethiopia Wildlife and Natural History Society, and our colleagues who assisted with Egyptian vulture trapping, including Emrah Çoban, Lale Aktay, Kayahan Agirkaya, Berkan Demir, Mete Türkoglu (Turkey); Karen Aghababyan, Anush Khachatrian, Garo Kurginyan (Armenia); Sisay Seyfu, Alazar Daka Rufo, Yilma Dellelegn Abebe, Girma Ayalew (Ethiopia); Svetoslav Spasov, Ivaylo Angelov, Saniye Mumun, Dobromir Dobrev, Tsvetomira Angelova, Stoycho Stoychev, (Bulgaria); Ewan and Jenny Weston, Emil Yordanov who assisted with Egyptian vulture trapping in Bulgaria Vasilis Sideris, Giannis Chondros, Christos Lambris, Antonis Vroikos, Dimitris Vavylis,

\section{REFERENCES}

Abrahms, B., Seidel, D. P., Dougherty, E., Hazen, E. L., Bograd, S. J., Wilson, A. M., et al. (2017). Suite of simple metrics reveals common movement syndromes across vertebrate taxa. Move. Ecol. 5:12. doi: 10.1186/s40462-017-0104-2

Agostini, N., Panuccio, M., and Pasquaretta, C. (2015). Morphology, flight performance, and water crossing tendencies of Afro-Palearctic raptors during migration. Curr. Zool. 61, 951-958. doi: 10.1093/czoolo/61.6.951

Alarcón, P. A. E., and Lambertucci, S. A. (2018). A three-decade review of telemetry studies on vultures and condors. Move. Ecol. 6, 13-13. doi: 10.1186/s40462-018-0133-5

Alerstam, T. (2003). "Bird migration speed," in Avian Migration, eds. P. Berthold, E. Gwinner, and E. Sonnenschein (Berlin: Springer-Verlag), 253-267.
Angelos Evangelidis (Greece), Mirjan Topi (Albania), Metodija Velevski and Zlatko Angeleski (North Macedonia). State Nature Reserve "Dagestanskiy" and Russian Raptor Research and Conservation Network supported work in Dagestan. Western Europe data: For deployments in Spain we thank the following people and organizations for assisting with field work, capture of the vultures and all other aspects of the study: L. Bolonio, J. de Lucas, V. Garcíia, R. Ibanez, M. Nieto, and A. Vela (Castellón and Guadalajara provinces, Spain); Luis Lopo, Ignacio Gámez, Francisco Javier Robres, Sandra Vela, Lidia Crespo, Diego García, Sergio Mikolta, Miguel Ángel Elvira, Carlos Fernández, Sara Josefa Herrero, Álvaro Alonso, Eduardo Miera, Miguel Ángel Marín and José Francisco Pedreño (La Rioja Goverment, Logroño province, Spain); José María Fernández, Iñigo Mendiola, Ibai Aizpuru, Fermín Ansorregi, Aitor Galdos, Aitor Lekuona, Mikel Olano, Jon Ugarte and Javier Vázquez (Fundación Hazi and Diputación Foral de Gipuzkoa, Guipúzcoa province, Spain); Saloro S.L.U. generously contributed data from the Duero region of Spain; the GREFA veterinary team and all who contributed to GREFA's project. For deployments in Portugal we thank EU-funded LIFE Rupis project partners (Sociedade Portuguesa para o Estudo da Aves; Associação Transumância e Natureza; Associação de Conservação da Natureza e do Património Rural; Guarda Nacional Republicana, Portugal; Fundación Patrimonio Natural de Castilla y León; EDP Distribuição-Energia SA; Instituto da Conservação da Natureza e Florestas, Portugal; Junta de Castilla y León, Spain; the MAVA Foundation); and the collaboration of Víctor García Matarranz (Ministerio de Agricultura y Pesca, Alimentación y Medio Ambiente, Spain). Parc National des Pyrénées-La salsepareille supported work in France. Middle East data: We thank the Israel Nature and Parks Authority (INPA) for their support of this project and specifically to Ohad Hatzofe and Ygal Miller for leading the conservation of vultures in Israel. We also thank Walter Nesser, for voluntarily assisting with field work.

\section{SUPPLEMENTARY MATERIAL}

The Supplementary Material for this article can be found online at: https://www.frontiersin.org/articles/10.3389/fevo. 2019.00323/full\#supplementary-material 
Bauer, S., Shamoun-Baranes, J., Nilsson, C., Farnsworth, A., Kelly, J. F., Reynolds, D. R., et al. (2018). The grand challenges of migration ecology that radar aeroecology can help answer. Ecography 42, 861-875. doi: 10.1111/ecog.04083

Bell, A. M., Hankison, S. J., and Laskowski, K. L. (2009). The repeatability of behaviour: a meta-analysis. Anim. Behav. 77, 771-783. doi: 10.1016/j.anbehav.2008.12.022

BirdLife International (2019). Species Factsheet: Neophron Percnopterus. Available online at: http://www.birdlife.org (accessed March 13, 2019).

Bodey, T. W., Cleasby, I. R., Bell, F., Parr, N., Schultz, A., Votier, S. C., et al. (2018). A phylogenetically controlled meta-analysis of biologging device effects on birds: deleterious effects and a call for more standardized reporting of study data. Methods Ecol. Evol. 9, 946-955. doi: 10.1111/2041-210X.12934

Both, C. (2010). Flexibility of timing of avian migration to climate change masked by environmental constraints en route. Curr. Biol. 20, 243-248. doi: 10.1016/j.cub.2009.11.074

Botha, A. J., Andevski, J., Bowden, C. G. R., Gudka, M., Safford, R. J., Tavares, J., et al. (2017). "Multi-species action plan to conserve African-Eurasian Vultures", in Animals (Abu Dhabi: Coordinating Unit of the CMS Raptors MOU).

Buechley, E. R., McGrady, M. J., Çoban, E., and Sekercioglu, Ç.H. (2018a). Satellite tracking a wide-ranging endangered vulture species to target conservation actions in the Middle East and East Africa. Biodiversity Conserv. 27, 2293-2310 doi: 10.1007/s10531-018-1538-6

Buechley, E. R., Oppel, S., Beatty, W. S., Nikolov, S. C., Dobrev, V., Arkumarev, V., et al. (2018b). Identifying critical migratory bottlenecks and high-use areas for an endangered migratory soaring bird across three continents. J. Avian Biol. 49:e01629. doi: 10.1111/jav.01629

Bunnefeld, N., Börger, L., van Moorter, B., Rolandsen, C. M., Dettki, H., Solberg, E. J., et al. (2011). A model-driven approach to quantify migration patterns: individual, regional and yearly differences. J. Anim. Ecol. 80, 466-476. doi: 10.1111/j.1365-2656.2010.01776.x

Calenge, C. (2006). The package "adehabitat" for the R software: a tool for the analysis of space and habitat use by animals. Ecol. Model. 197, 516-519. doi: 10.1016/j.ecolmodel.2006.03.017

Caucanas, G., Piot, B., Barlow, C. R., and Phipps, W. L. (2018). A major count of Egyptian Vultures Neophron percnopterus from Senegal in November 2017 at the Boundou Community Nature Reserve, with notes on its history and current status in Senegal and The Gambia. Malimbus 40, 55-66.

Choi, C.-Y., Peng, H.-B., He, P., Ren, X.-T., Zhang, S., Jackson, M. V., et al. (2019). Where to draw the line? Using movement data to inform protected area design and conserve mobile species. Biol. Conserv. 234, 64-71. doi: 10.1016/j.biocon.2019.03.025

Clark, W., and Schmitt, N. (1998). Ageing Egyptian vultures. Alula 4, 122-127.

Cohen, E. B., Hostetler, J. A., Hallworth, M. T., Rushing, C. S., Sillett, T. S., and Marra, P. P. (2018). Quantifying the strength of migratory connectivity. Methods Ecol. Evol. 9, 513-524. doi: 10.1111/2041-210X.12916

Dodge, S., Bohrer, G., Bildstein, K., Davidson, S. C., Weinzierl, R., Bechard, M. J., et al. (2014). Environmental drivers of variability in the movement ecology of turkey vultures (Cathartes aura) in North and South America. Philosoph. Transac. R. Soc. B Biol. Sci. 369:1643. doi: 10.1098/rstb.2013.0195

Douglas, D. C., Weinzierl, R., C., Davidson, S., Kays, R., Wikelski, M., and Bohrer, G. (2012). Moderating Argos location errors in animal tracking data. Methods Ecol. Evol. 3, 999-1007. doi: 10.1111/j.2041-210X.2012.00245.x

Dray, S., and Dufour, A. (2007). The ade4 Package: implementing the duality diagram for ecologists. J. Stat. Softw. 22, 1-20. doi: 10.18637/jss.v022.i04

Duriez, O., Peron, G., Gremillet, D., Sforzi, A., and Monti, F. (2018). Migrating ospreys use thermal uplift over the open sea. Biol. Lett. 14:20180687. doi: $10.1098 / \mathrm{rsbl} .2018 .0687$

ESRI (2014). “ArcMap”. 10.2.2 ed. Oaklands, CA: ESRI.

Finch, T., Butler, S. J., Franco, A. M. A., and Cresswell, W. (2017). Low migratory connectivity is common in long-distance migrant birds. J. Anim. Ecol. 86, 662-673. doi: 10.1111/1365-2656.12635

Fraser, K. C., Davies, K. T. A., Davy, C. M., Ford, A. T., Flockhart, D. T. T., and Martins, E. G. (2018). Tracking the conservation promise of movement ecology. Front. Ecol. Evol. 6:150. doi: 10.3389/fevo.2018.00150

Garcia-Ripolles, C., and Lopez-Lopez, P. (2006). Population size and breeding performance of Egyptian vultures (Neophron percnopterus) in eastern Iberian Peninsula. J. Raptor Res. 40, 217-221. doi: 10.3356/08921016(2006)40[217:PSABPO]2.0.CO;2
García-Ripollés, C., López-López, P., and Urios, V. (2010). First description of migration and wintering of adult Egyptian Vultures Neophron percnopterus tracked by GPS satellite telemetry. Bird Study 57, 261-265. doi: 10.1080/00063650903505762

Kemp, M. U., Shamoun-Baranes, J., Van Gasteren, H., Bouten, W., and Van Loon, E. E. (2010). Can wind help explain seasonal differences in avian migration speed? J. Avian Biol. 41, 672-677. doi: 10.1111/j.1600-048X.2010.05053.x

Klaassen, R. H. G., Hake, M., Strandberg, R., Koks, B. J., Trierweiler, C., Exo, K.M., et al. (2014). When and where does mortality occur in migratory birds? Direct evidence from long-term satellite tracking of raptors. J. Anim. Ecol. 83, 176-184. doi: 10.1111/1365-2656.12135

Kölzsch, A., Müskens, G. J. D. M., Kruckenberg, H., Glazov, P., Weinzierl, R., Nolet, B. A., et al. (2016). Towards a new understanding of migration timing: slower spring than autumn migration in geese reflects different decision rules for stopover use and departure. Oikos 125, 1496-1507. doi: 10.1111/oik.03121

Lefcheck, J. S. (2016). piecewiseSEM: piecewise structural equation modelling in $\mathrm{r}$ for ecology, evolution, and systematics. Methods Ecol. Evol. 7, 573-579. doi: 10.1111/2041-210X.12512

Lieury, N., Gallardo, M., Ponchon, C., Besnard, A., and Millon, A. (2015). Relative contribution of local demography and immigration in the recovery of a geographically-isolated population of the endangered Egyptian vulture. Biol. Conserv. 191, 349-356. doi: 10.1016/j.biocon.2015.07.008

Lindström, A., Alerstam, T., and Hedenström, A. (2019). Faster fuelling is the key to faster migration. Nat. Clim. Change 9, 288-289. doi: 10.1038/s41558-019-0443-7

López-López, P. (2016). Individual-based tracking systems in ornithology: welcome to the Era of Big Data. Ardeola 63, 103-136. doi: 10.13157/arla.63.1.2016.rp5

López-López, P., García-Ripollés, C., and Urios, V. (2014). Individual repeatability in timing and spatial flexibility of migration routes of trans-Saharan migratory raptors. Curr. Zool. 60, 642-652. doi: 10.1093/czoolo/60.5.642

Mallory, M. L., and Gilbert, C. D. (2008). Leg-loop harness design for attaching external transmitters to seabirds. Marine Ornithol. 36, 183-188.

Mandel, J. T., Bohrer, G., Winkler, D. W., Barber, D. R., Houston, C. S., and Bildstein, K. L. (2011). Migration path annotation: cross-continental study of migration-flight response to environmental conditions. Ecol. Appl. 21, 2258-2268. doi: 10.1890/10-1651.1

Martell, M. S., Bierregaard, R. O., Washburn, B. E., Elliott, J. E., Henny, C. J., Kennedy, R. S., et al. (2014). The spring migration of adult North American Ospreys. J. Raptor Res. 48, 309-324. doi: 10.3356/JRR-14-00035.1

Martín, B., Onrubia, A., de la Cruz, A., and Ferrer, M. (2016). Trends of autumn counts at Iberian migration bottlenecks as a tool for monitoring continental populations of soaring birds in Europe. Biodiversity Conserv. 25, 295-309. doi: 10.1007/s10531-016-1047-4

McGrady, M. J., Karelus, D. L., Rayaleh, H. A., Sarrouf Willson, M., Meyburg, B. U., Oli, M. K., et al. (2018). Home ranges and movements of Egyptian Vultures Neophron percnopterus in relation to rubbish dumps in Oman and the Horn of Africa. Bird Study 65, 544-556. doi: 10.1080/00063657.2018. 1561648

McKinnon, E. A., and Love, O. P. (2018). Ten years tracking the migrations of small landbirds: lessons learned in the golden age of bio-logging. The Auk 135, 834-856, 823. doi: 10.1642/AUK-17-202.1

Meyburg, B.-U., Gallardo, M., Meyburg, C., and Dimitrova, E. (2004). Migrations and sojourn in Africa of Egyptian vultures (Neophron percnopterus) tracked by satellite. J. Ornithol. 145, 273-280. doi: 10.1007/s10336-004-0037-6

Monti, F., Grémillet, D., Sforzi, A., Dominici, J. M., Bagur, R. T., Navarro, A. M., et al. (2018). Migration distance affects stopover use but not travel speed: contrasting patterns between long- and short-distance migrating ospreys. $J$. Avian Biol. 49:e01839. doi: 10.1111/jav.01839

Nakagawa, S., and Schielzeth, H. (2010). Repeatability for Gaussian and nonGaussian data: a practical guide for biologists. Biol. Rev. 85, 935-956. doi: 10.1111/j.1469-185X.2010.00141.x

Nakagawa, S., and Schielzeth, H. (2013). A general and simple method for obtaining R2 from generalized linear mixed-effects models. Methods Ecol. Evol. 4, 133-142. doi: 10.1111/j.2041-210x.2012.00261.x

Nilsson, C., Klaassen, R. H. G., and Alerstam, T. (2013). Differences in speed and duration of bird migration between Spring and Autumn. Am. Natural. 181, 837-845. doi: 10.1086/670335 
Oppel, S., Dobrev, V., Arkumarev, V., Saravia, V., Bounas, A., Kret, E., et al. (2015). High juvenile mortality during migration in a declining population of a long-distance migratory raptor. Ibis 157, 545-557. doi: 10.1111/ibi.12258

Panuccio, M., Agostini, N., and Premuda, G. (2012). Ecological barriers promote risk minimisation and social learning in migrating short-toed snake eagles. Ethol. Ecol. Evol. 24, 74-80. doi: 10.1080/03949370.2011.583692

Patchett, R., Finch, T., and Cresswell, W. (2018). Population consequences of migratory variability differ between flyways. Curr. Biol. 28, R340-R341. doi: $10.1016 /$ j.cub.2018.03.018

R Core Team (2018). R: A Language and Environment for Statistical Computing. Vienna: R Foundation for Statistical Computing.

Rotics, S., Kaatz, M., Turjeman, S., Zurell, D., Wikelski, M., Sapir, N., et al. (2018). Early arrival at breeding grounds: causes, costs and a trade-off with overwintering latitude. J. Anim. Ecol. 87, 1627-1638. doi: $10.1111 / 1365-2656.12898$

Safford, R., Andevski, J., Botha, A., Bowden, C. G. R., Crockford, N., Garbett, R., et al. (2019). Vulture conservation: the case for urgent action. Bird Conserv. Int. 29, 1-9. doi: 10.1017/S0959270919000042

Sanz-Aguilar, A., De Pablo, F., and Donázar, J. A. (2015). Age-dependent survival of island vs. mainland populations of two avian scavengers: delving into migration costs. Oecologia 179, 405-414. doi: 10.1007/s00442-015-3355-x

Schlaich, A. E., Bouten, W., Bretagnolle, V., Heldbjerg, H., Klaassen, R. H. G., Sørensen, I. H., et al. (2017). A circannual perspective on daily and total flight distances in a long-distance migratory raptor, the Montagu's harrier, Circus pygargus. Biol. Lett. 13:20170073. doi: 10.1098/rsbl.2017.0073

Schmaljohann, H. (2018). Proximate mechanisms affecting seasonal differences in migration speed of avian species. Sci. Rep. 8:4106. doi: 10.1038/s41598-018-22421-7

Scott, R., Marsh, R., and Hays, G. C. (2014). Ontogeny of long distance migration. Ecology 95, 2840-2850. doi: 10.1890/13-2164.1

Sergio, F., Tanferna, A., Blas, J., Blanco, G., and Hiraldo, F. (2019). Reliable methods for identifying animal deaths in GPS- and satellitetracking data: review, testing, and calibration. J. Appl. Ecol. 56, 562-572. doi: 10.1111/1365-2664.13294

Sergio, F., Tanferna, A., De Stephanis, R., Jiménez, L. L., Blas, J., and Hiraldo, F. (2017). Migration by breeders and floaters of a long-lived raptor: implications for recruitment and territory quality. Anim. Behav. 131, 59-72. doi: 10.1016/j.anbehav.2017.07.011

Sergio, F., Tanferna, A., De Stephanis, R., Jiménez, L. L., Blas, J., Tavecchia, G., et al. (2014). Individual improvements and selective mortality shape lifelong migratory performance. Nature 515:410. doi: 10.1038/nature13696

Sergio, F., Tavecchia, G., Tanferna, A., López Jiménez, L., Blas, J., De Stephanis, R., et al. (2015). No effect of satellite tagging on survival, recruitment, longevity, productivity and social dominance of a raptor, and the provisioning and condition of its offspring. J. Appl. Ecol. 52, 1665-1675. doi: $10.1111 / 1365-2664.12520$

Shamoun-Baranes, J., Baharad, A., Alpert, P., Berthold, P., Yom-Tov, Y., Dvir, Y., et al. (2003). The effect of wind, season and latitude on the migration speed of white storks Ciconia ciconia, along the Eastern Migration Route. J. Avian Biol. 34, 97-104. doi: 10.1034/j.1600-048X.2003.03079.x

Signer, J., Fieberg, J., and Avgar, T. (2019). Animal movement tools (amt): R package for managing tracking data and conducting habitat selection analyses. Ecol. Evol. 9, 880-890. doi: 10.1002/ece3.4823

Spitz, D. B., Hebblewhite, M., and Stephenson, T. R. (2017). “MigrateR”: extending model-driven methods for classifying and quantifying animal movement behavior. Ecography 40, 788-799. doi: 10.1111/ecog.02587

Stoffel, M. A., Nakagawa, S., and Schielzeth, H. (2017). rptR: repeatability estimation and variance decomposition by generalized linear mixedeffects models. Methods Ecol. Evol. 8, 1639-1644. doi: 10.1111/2041-210 X.12797

Strandberg, R., Klaassen, R. H. G., Hake, M., and Alerstam, T. (2010). How hazardous is the Sahara Desert crossing for migratory birds? Indications from satellite tracking of raptors. Biol. Lett. 6, 297-300. doi: 10.1098/rsbl. 2009.0785
Trierweiler, C., Klaassen, R. H. G., Drent, R. H., Exo, K.-M., Komdeur, J., Bairlein, F., et al. (2014). Migratory connectivity and population-specific migration routes in a long-distance migratory bird. Proc. R. Soc. B. Biol. Sci. 281:1778. doi: $10.1098 /$ rspb.2013.2897

Tucker, M. A., Böhning-Gaese, K., Fagan, W. F., Fryxell, J. M., Van Moorter, B., Alberts, S. C., et al. (2018). Moving in the Anthropocene: global reductions in terrestrial mammalian movements. Science 359, 466-469. doi: 10.1126/science.aam 9712

Vansteelant, W. M. G., Bouten, W., Klaassen, R. H. G., Koks, B. J., Schlaich, A. E., van Diermen, J., et al. (2015). Regional and seasonal flight speeds of soaring migrants and the role of weather conditions at hourly and daily scales. J. Avian Biol. 46, 25-39. doi: 10.1111/jav.00457

Vansteelant, W. M. G., Kekkonen, J., and Byholm, P. (2017). Wind conditions and geography shape the first outbound migration of juvenile honey buzzards and their distribution across sub-Saharan Africa. Proc. Biol. Sci. 284:20170387. doi: $10.1098 /$ rspb.2017.0387

Vardanis, Y., Nilsson, J.-̊., Klaassen, R. H. G., Strandberg, R., and Alerstam, T. (2016). Consistency in long-distance bird migration: contrasting patterns in time and space for two raptors. Anim. Behav. 113, 177-187. doi: 10.1016/j.anbehav.2015.12.014

Velevski, M., Nikolov, S. C., Hallmann, B., Dobrev, V., Sidiropoulos, L., Saravia, V., et al. (2015). Population decline and range contraction of the Egyptian Vulture Neophron percnopterus on the Balkan Peninsula. Bird Conserv. Int. 25, 440-450. doi: $10.1017 /$ S0959270914000343

Vidal-Mateo, J., Mellone, U., López-López, P., La Puente, J. D., García-Ripollés, C., Bermejo, A., et al. (2016). Wind effects on the migration routes of trans-Saharan soaring raptors: geographical, seasonal, and interspecific variation. Curr. Zool. 62, 89-97. doi: 10.1093/cz/zow008

Webster, M. S., Marra, P. P., Haig, S. M., Bensch, S., and Holmes, R. T. (2002). Links between worlds: unraveling migratory connectivity. Trends Ecol. Evol. 17, 76-83. doi: 10.1016/S0169-5347(01)02380-1

Welch, G., and Welch, H. (1988). The autumn migration of raptors and other soaring birds across the Bab-el-Mandeb straits. Sandgrouse 10, 26-50.

Whelan, C. J., Sekercioglu, Ç. H., and Wenny, D.G. (2015). Why birds matter: from economic ornithology to ecosystem services. J. Ornithol. 156, 227-238. doi: 10.1007/s10336-015-1229-y

Wikelski, M., and Kays, R. (2019). Movebank: Archive, Analysis and Sharing of Animal Movement Data. Available online at: http://www.movebank.org (accessed January 02, 2019).

Zuur, A. F., Ieno, E. N., Walker, N. J., Saveliev, A., and Smith, G. M. (2009). Mixed Effects Models and Extensions in Ecology With R. New York, NY: Springer.

Conflict of Interest Statement: IK was employed by company Sibecocentar LLC, Russia; IA was employed by SALORO, Spain; and JJ was employed by Oriolus Ambiente e Eco Turismo LDA, Spain.

The remaining authors declare that the research was conducted in the absence of any commercial or financial relationships that could be construed as a potential conflict of interest.

The reviewer, TF, declared a shared affiliation, with no collaboration, with one of the authors, $\mathrm{SO}$, to the handling editor at the time of review.

Copyright (C) 2019 Phipps, López-López, Buechley, Oppel, Álvarez, Arkumarev, Bekmansurov, Berger-Tal, Bermejo, Bounas, Alanís, de la Puente, Dobrev, Duriez, Efrat, Fréchet, García, Galán, García-Ripollés, Gil, Iglesias-Lebrija, Jambas, Karyakin, Kobierzycki, Kret, Loercher, Monteiro, Morant Etxebarria, Nikolov, Pereira, Peške, Ponchon, Realinho, Saravia, Şekercioğlu, Skartsi, Tavares, Teodósio, Urios and Vallverdú. This is an open-access article distributed under the terms of the Creative Commons Attribution License (CC BY). The use, distribution or reproduction in other forums is permitted, provided the original author(s) and the copyright owner(s) are credited and that the original publication in this journal is cited, in accordance with accepted academic practice. No use, distribution or reproduction is permitted which does not comply with these terms. 